\title{
THE EFFECT OF NASCENT HYDROGEN ON HARD STEEL MAGNETS.
}

\author{
By John Coulson.
}

SyNOPSIS.

\begin{abstract}
Aging Effect of Nascent Hydrogen on the Magnetic Moment of Hardened Steel Magnets.-When magnets, well seasoned by repeated heating and cooling, are exposed to the action of nascent hydrogen by being made cathodes in a sulfuric acid bath, the magnetic moment decreases, reaching in time a permanent value from 5 to 20 per cent. less than the original moment. The aging process is accelerated by raising the temperature of the electrolyte, the total time required being only one hour or less at $60^{\circ} \mathrm{C}$. For drill rod (carbon I.2 per cent.), quenched from $800^{\circ} \mathrm{C}$., the change occurs gradually; but for tungsten magnet steel most of the decrease occurs suddenly after an exposure which, for the electrolyte at $60^{\circ} \mathrm{C}$., varies from 3 to 15 minutes as the quenching temperature is increased from 700 . to $850^{\circ} \mathrm{C}$., the corresponding sudden changes in moment decreasing from I 9 to 4 per cent. The behavior of spring steel (carbon 0.8 per cent.) is very similar, but the sudden changes occur later. After aging in this way, hammering the magnets has practically no effect.

Penetration of Nascent Hydrogen into Mild Steel.-Photographs of fractured cold-rolled rods show that in 40 seconds the hydrogen penetrated about $\mathrm{I} \mathrm{mm}$.
\end{abstract}

卫H

E magnetic moment of permanent magnets changes quite perceptibly even following the most careful "aging"1 after magnetization. This so-called aging effect goes on at a diminishing rate notwithstanding such magnets be kept isolated in a neutral field. The desirability of hastening the final condition, where the magnetic moment ceases to change, led to the present investigation.

Bar magnets of "Special Alloy Magnet Steel" and high carbon steels were treated electrolytically in a strongly acidulated electrolyte. It was found that the magnetic moment of magnets treated as cathode undergoes a marked diminution, and that the character of the change depends on the nature of the steel and on the hardening temperature.

Careful and elaborate investigations have shown that steel absorbs hydrogen and other gases, and the effect of such gases on the mechanical properties of the metal has been studied in detail. ${ }^{2}$ Most of this work,

${ }^{1}$ Wiedemann, Pogg. Ann., I852, I858, r864. Dufour, Pogg. Ann., 99, I855; Arch. de Geneve, I857. Favé, Comptes Rendus, 72, I876. Gaugain, Comptes Rendus, 72, I876. Trowbridge, Am. Jour. of Science, I88I. Kohlrausch, Wied. Ann., I884. Barus and Strouhal, Bulletin of the U. S. Geological Survey, No. I4, I88.5. Peirce, Am. Jour. of Science, I896. Durward, Am. Jour. of Science, I898. Peirce, Proc. Amer. Acad. Arts and Sciences, I905.

${ }^{2}$ Bellock, Comptes Rendus, I49, I909. Richards and Behr, Zeitschr. Phys. Chem., 58, 
however, has been carried out on steels which were exposed to the gases at temperatures considerably above normal or room temperature. It is not generally accepted that steel absorbs hydrogen to any extent at normal temperatures, therefore, hydrogen is not considered to play here a vital part at ordinary temperatures in the structural or other changes taking place in the metal. Nevertheless, the author, ${ }^{1}$ and others ${ }^{2}$ have found that nascent hydrogen penetrates steel surprisingly rapidly at temperatures as low as $20^{\circ} \mathrm{C}$.

The permeability of steel for hydrogen at these low temperatures suggested that the permanency of the magnetic moment of hardened steel magnets might well be influenced by the absorption of hydrogen. In the course of the investigation fifty or more bar magnets of length I4.4 $\mathrm{cm}$. were carefully made and tested for changes in the magnetic moment after treatment. Most of the specimens were quenched to glass hardness from $850^{\circ} \mathrm{C}$. Some were quenched at a lower temperature, about $700^{\circ} \mathrm{C}$. It will be seen that the hardening temperature is of great significance in the changes taking place within the steel when hydrogen is absorbed.

Following the hardening process the specimens were magnetized to saturation inside a solenoid many times their length. After removal from the solenoid care was taken to keep the magnets isolated from all magnetic material until their history had been completed. The usual fall in the magnetic moment of the magnets, due to repeated heating and cooling, was observed. This operation was continued until evidence of further change of magnetic moment had disappeared. The heating operation was carried out with the magnet sealed in an air-tight glass tube immersed in boiling water.

The preliminary aging having been completed, the magnet under test was subjected to the action of nascent hydrogen by making it the cathode in an electrolytic cell, while the lead container served as anode. The electrolyte used was a 25 per cent. solution of $\mathrm{H}_{2} \mathrm{SO}_{4}$, and the current through the cell was kept at 2 amperes. The magnets were exposed to the action of the hydrogen for increasing time intervals, at the outset, usually 15 or 30 seconds. After each exposure the magnetic moment of the magnet was measured at room temperature.

1907. Hein, Zeitschr. Phys. Chem., 58, 1907. Goutal, Comptes Rendus, 148, I909. Sieverts and Krumhaar, Berl. Deutsche Chem. Ges., 43, I9ro. Rumpf, Akad. Wiss. Wien, Sitz. Ber., Ir9, I910. Charpy, Bonnerot, Comptes Rendus, I52, I9II. Stead, Iron and Steel Industry, J., I03, I92I; Engineering, I Ir, I921. Thompson and Richardson, Met. and Chem. Eng., I6, I917. Smith, Am. Electro-Chem. Soc. J., I9I8.

${ }^{1}$ Coulson, Am. Electro-Chem. J., I9I 7.

${ }^{2}$ Bellaty and Lussana, R. Istituto Veneto Atti., I888; I89r. N. Cimento, 5, I9r3. Charpy and Bonnerot, Comptes Rendus, I52, I9Ir; I54, I9I2. Bellaty and Lussana, N. Cimento, 5, Ser. 6, 1913. 
The measurements were made by placing on the opposite side of a magnetometer a standard bar magnet in Gauss's A position, held, and protected completely from rapid temperature changes, within a wooden carriage sliding on a horizontal scale. This compensating magnet, having been fixed with its center at a convenient distance $d_{0}$ from the center of the magnetometer needle, brought the needle back into the meridian when the center of the magnet under observation was at the fixed distance $d$. Let $M_{0}$ be the magnetic moment of the standard magnet and $2 l_{0}$ its magnetic length, and let $M_{1}$ and $M_{1}{ }^{\prime}$ be the moments of the magnet under test, before and after treatment respectively, and $2 l$ its magnetic length. The needle will be deflected through the angle $\alpha$ so that

$$
\begin{gathered}
\frac{2 M_{0} d_{0}}{\left(d_{0}^{2}-l_{0}^{2}\right)^{2}}=\frac{2 M_{1} d}{\left(d^{2}-l^{2}\right)^{2}}, \\
\frac{2 M_{1} d}{\left(d^{2}-l^{2}\right)^{2}}-\frac{2 M_{1}^{\prime} d}{\left(d^{2}-l^{2}\right)^{2}}=\frac{2 d\left(M_{1}-M_{1}^{\prime}\right)}{\left(d^{2}-l^{2}\right)^{2}}=H \tan \alpha, \\
\frac{M_{1}-M_{1}^{\prime}}{M_{1}}=\frac{\left(d_{0}^{2}-l_{0}^{2}\right)^{2}}{2 M_{0} d_{0}} \cdot H \tan \alpha=\frac{\tan \alpha}{\tan \alpha_{0}},
\end{gathered}
$$

where $H$ is the horizontal component of the earth's magnetic field, and $\alpha_{0}$ is the angle through which $M_{0}$ would deflect the needle if $M_{1}$ were absent.

The method of procedure was then as follows:

The standard magnet was placed with its center at a known distance from the magnetometer, and its carriage clamped firmly in position. The magnet to be tested was placed on the opposite side of the magnetometer and adjusted in such position as to bring the needle back into the meridian. Its holder was then clamped and the distance of the center of the magnet from the magnetometer was recorded. After subjecting the magnet to treatment, it was placed again in its holder and the deflection of the magnetometer needle observed with the magnet at room tem perature. The dimensions and the magnetic moment of the standard magnet being known, the magnetic moment and the fractional loss of the moment of the magnet under test could be easily calculated from the above formulæ.

It may be of interest to say that the Special Magnet Steel was a tungsten alloy steel in the form of square bars $8.0 \mathrm{~mm}$. cross section, and was received direct from the Crucible Steel Co., Pittsburgh. The spring steel and polished drill rod were in the form of rods $6.4 \mathrm{~mm}$. in diameter, and were bought in the open market. The carbon content was about 0.80 and 1.20 respectively.

Typical results obtained with magnets of the above materials treated 
electrolytically at $20^{\circ} \mathrm{C}$. and $60^{\circ} \mathrm{C}$. are shown, some in tabular form, others by curves. Table I. and Fig. I are results obtained for magnets

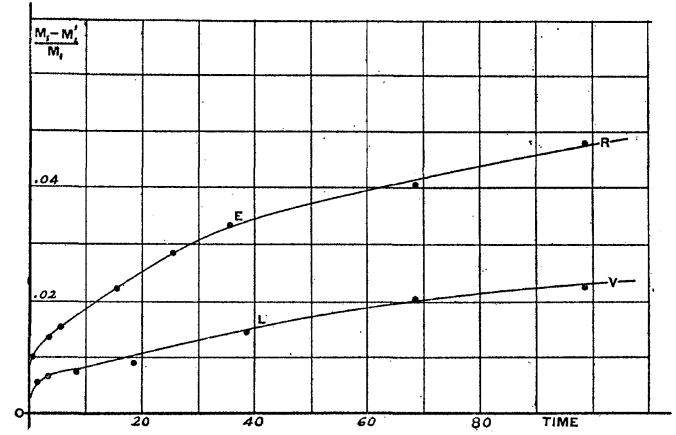

Fig. 1.

Shows the fractional change in the magnetic moment as a function of the time of exposure to the hydrogen at $20^{\circ} \mathrm{C}$. Polished drill rod: Curve $O E R$. Special alloy magnet steel: Curve $O L V$.

treated at $20^{\circ} \mathrm{C}$. The fractional loss of magnetic moment and the corresponding time exposure of the magnet to the action of the hydrogen are given. The upper section of the table and the curve $O E R$ of the figure represent observations made on two magnets of drill rod, of which many were tested. For like treatment the results were in very good agreement. Representative data are given in the lower half of the table for a magnet of spring steel, and similar data for a magnet of special magnet steel are shown in curve form, Curve $O L V$, of the figure.

\begin{tabular}{c|c|c|c|c|c|c}
\multicolumn{2}{c}{ TABLE I. } \\
\hline History. & $\begin{array}{c}\text { Exposure } \\
\text { (Minutes) }\end{array}$ & $\begin{array}{c}M_{1}-M_{1}^{\prime} . \\
M_{1}\end{array}$ & $M$. & $\begin{array}{c}\text { Exposure } \\
\text { (Minutes) }\end{array}$ & $\frac{M_{1}-M_{1^{\prime}}}{M_{1}}$ & $M$. \\
\hline Drill Rod. & 0 & & 1836 & 20.0 & .0245 & 1788 \\
Quenched from 800 C. & 1.0 & .0120 & 1814 & 30.0 & .0270 & 1786 \\
Magnetic moment after & 3.0 & .0150 & 1809 & 40.0 & .0302 & 1781 \\
magnetization, & 5.0 & .0168 & 1805 & 50.0 & .0320 & 1777 \\
$M=1836$. & 10.0 & .0198 & 1800 & 60.0 & .0342 & 1773 \\
\hline Spring Steel. & 0 & & 1919 & 20.0 & .0130 & 1894 \\
\hline Quenched at 850 C. & 0.5 & .0030 & 1913 & 30.0 & .0142 & 1892 \\
Magnetic moment after & 1.5 & .0046 & 1910 & 40.0 & .0158 & 1889 \\
magnetization, & 3.0 & .0070 & 1906 & 50.0 & .0170 & 1886 \\
$M=1919$. & 5.0 & .0090 & 1902 & 60.0 & .0175 & 1885 \\
& 10.0 & .0111 & 1898 & 70.0 & .0180 & 1884 \\
\hline
\end{tabular}

Temperature of exposure: electrolyte kept at $20^{\circ} \mathrm{C}$.

Magnets made from drill rod, treated electrolytically, show a greater 
aging effect than magnets of the other steels. The spring steel magnets change more slowly at the outset than those of special magnet steel, but after 50 minutes' exposure, approximately, the fractional decrease of their respective moments had the same value. Usually after this stage the loss in magnetic moment for magnets of spring steel was greater than for the special magnet steel. From two to three hours' exposure to the electrolytic hydrogen decreased the magnetic moment of the magnet to a fixed value. Hammering the magnets had little or no effect in changing further their magnetic moment. Careful weighing before and after treatment showed that the magnets did not lose weight during exposure.

Numerous magnets of spring steel and special magnet steel, treated at $20^{\circ} \mathrm{C}$., showed a sudden drop in magnetic moment before reaching a constant value. It occurred usually after an hour's treatment or more and was of a magnitude of one or two per cent. The change before and after being only a fraction of one per cent.

The rapidity with which the magnetic moment settles to a final value depends on the temperature of the electrolyte in which the magnets are brought under the action of the electrolytically evolved hydrogen. Moreover, the transition to this final state, due to the action of the hydrogen, is surprisingly different for the various specimens.

TABLE II.

\begin{tabular}{|c|c|c|c|c|c|c|}
\hline History. & $\begin{array}{l}\text { Exposure } \\
\text { (Minutes). }\end{array}$ & $\frac{M_{1}-M_{1}^{\prime}}{M_{1}}$ & $M$ & $\begin{array}{l}\text { Exposure } \\
\text { (Minutes). }\end{array}$ & $\frac{M_{1}-M_{1}^{\prime}}{M_{1}}$ & $M$ \\
\hline $\begin{array}{l}\text { Drill Rod. } \\
\text { Quenched from } 800^{\circ} \mathrm{C} \text {. } \\
\text { Magnetic moment after } \\
\text { repeated heating and } \\
\text { cooling, } \\
M=2040\end{array}$ & $\begin{array}{c}0 \\
0.5 \\
1.0 \\
3.0 \\
5.0 \\
10.0 \\
20.0\end{array}$ & $\begin{array}{l}.0150 \\
.0259 \\
.0585 \\
.0820 \\
.0881 \\
.095\end{array}$ & $\begin{array}{l}2040 \\
2010 \\
1987 \\
1921 \\
1873 \\
1860 \\
1846\end{array}$ & $\begin{array}{l}30.0 \\
40.0 \\
50.0 \\
60.0 \\
80.0 \\
90.0\end{array}$ & $\begin{array}{l}.101 \\
.109 \\
.116 \\
.121 \\
.127 \\
.129\end{array}$ & $\begin{array}{l}1834 \\
1816 \\
1804 \\
1793 \\
1781 \\
1777\end{array}$ \\
\hline $\begin{array}{c}\text { Special Alloy Magnet } \\
\text { Steel. } \\
\text { Original magnet } \\
\text { moment, } M=1761 . \\
\text { Moment after repeated } \\
\text { heating and cooling, } \\
\qquad M=1697 . \\
\text { After being dropped } 1 \mathrm{ft} . \\
\text { end on fifty times on a } \\
\text { block of stone } \ldots . . . . .\end{array}$ & $\begin{array}{l}0 \\
0.5 \\
2.0 \\
5.0\end{array}$ & $\begin{array}{l}.0009 \\
.0097 \\
.0115\end{array}$ & $\begin{array}{l}1697 \\
1695 \\
1680 \\
1677\end{array}$ & $\begin{array}{l}10.0 \\
20.0 \\
25.0 \\
35.0\end{array}$ & $\begin{array}{l}.0129 \\
.0538 \\
.0550 \\
.0565\end{array}$ & $\begin{array}{l}1675 \\
1650 \\
1603 \\
1601\end{array}$ \\
\hline
\end{tabular}

Temperature of exposure: electrolyte kept at $60^{\circ} \mathrm{C}$. 
Table II. and Fig. 2 show results obtained for magnets of different

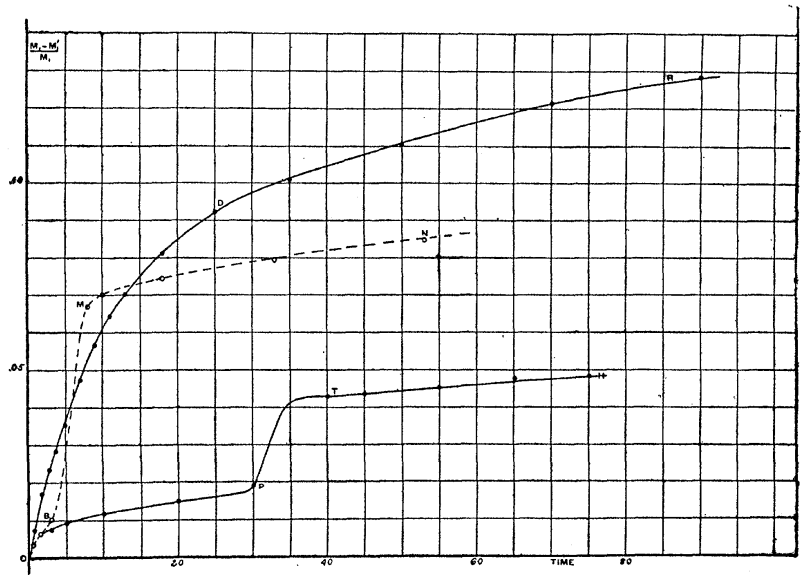

Fig. 2.

Shows the fractional change in the magnetic moment as a function of the time of exposure to the hydrogen at $60^{\circ} \mathrm{C}$. Polished drill rod: Curve $O D R$. Special alloy magnet steel: Curve $O M N$. Spring steel: Curve $O P T H$.

material, treated at $60^{\circ} \mathrm{C}$. The upper section of the table and the Curve $O D R$ of the figure are for magnets made from polished drill rod, quenched at slightly different temperatures to glass hardness. As will be seen, the magnitude of the aging is not the same for the two magnets, but the character of the results is very similar. The final value of the magnetic moment is reached in approximately the same time of exposure. The decrease being about I 4 per cent.

The broken Curve $O M N$ of the figure and the results tabulated in the lower portion of the table illustrate the character of this aging process on magnets of special alloy magnet steel. The quenching temperature for these magnets differed by about $50^{\circ} \mathrm{C}$. The specimen quenched at the lower temperature, $800^{\circ} \mathrm{C}$., and indicated by the curve shows a very sudden change in magnetic moment after a few minutes' exposure to the hydrogen in the heated electrolyte. For the specimen quenched at the higher temperature, $850^{\circ} \mathrm{C}$., this sudden fall in magnetic moment takes place after a longer exposure. This sudden change in moment is, also, very marked in the case of magnets made of spring steel, but it takes place usually after 20 or 30 minutes' exposure. The curve $O P T H$ of the figure is a fair example of results obtained for specimens of this steel when quenched glass hard. Examination of the results will show that after this sudden transition took place the change in the magnetic moment was comparatively small, even after prolonged exposure. Hammering the magnets at this stage caused practically no alteration of the magnetic moment. 
This precipitous change in the magnetic moment of magnets made from special magnet steel and from spring steel appears to be considerably magnified when the specimens are quenched at temperatures below $850^{\circ} \mathrm{C}$. Table III. shows results obtained with a magnet of special magnet steel quenched at $700^{\circ} \mathrm{C}$. These results are shown graphically in Fig. 3, curve PRTE. Examination will show that after 2 minutes'

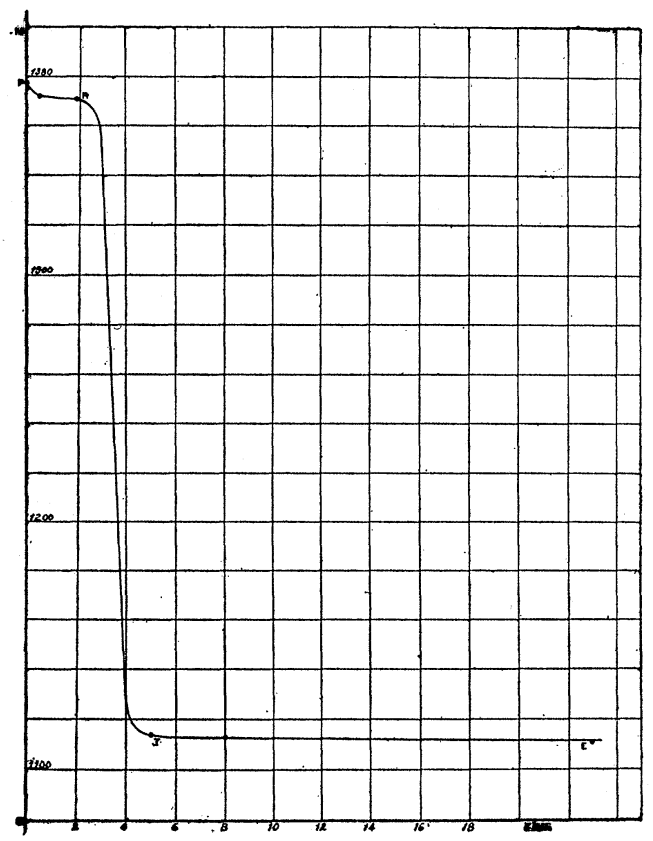

Fig. 3.

Shows the moment of a magnet of special alloy magnet steel quenched at $700^{\circ} \mathrm{C}$., as a function of the time of exposure to the hydrogen. Temperature of the electrolyte $60^{\circ} \mathrm{C}$.

TABLE III.

\begin{tabular}{c|c|c|c}
\hline History. & $\begin{array}{c}\text { Exposure } \\
\text { (Minutes). }\end{array}$ & $\frac{M_{1}-M^{\prime}}{M_{1}}$ & $M$. \\
\hline $\begin{array}{c}\text { Quenched from } 700^{\circ} \mathrm{C} . \\
M=1452 .\end{array}$ & 0 & & 1378 \\
Magnetic moment after magnetization, & 0.5 & .0043 & 1372 \\
$M=1450$ & .0046 & 1371 \\
Moment after repeated heating and cooling, & 5.0 & .1916 & 1114 \\
$M=1378$. & 8.0 & .1921 & 1113 \\
& 13.0 & .1921 & 1113 \\
& 23.0 & .1927 & 1112 \\
\hline
\end{tabular}

Special Alloy Magnet Steel.

Temperature of exposure: electrolyte kept at $60^{\circ} \mathrm{C}$. 
exposure to the electrolytic hydrogen the magnetic moment of the magnet dropped more than 9 per cent., while up to this point the decrease in magnetic moment was only a small fraction of one per cent. After the sudden change occurred, further exposures to the hydrogen had practically no effect on the magnetic moment.

Fig. 4, which is taken from an earlier paper, ${ }^{1}$ illustrates the rapidity

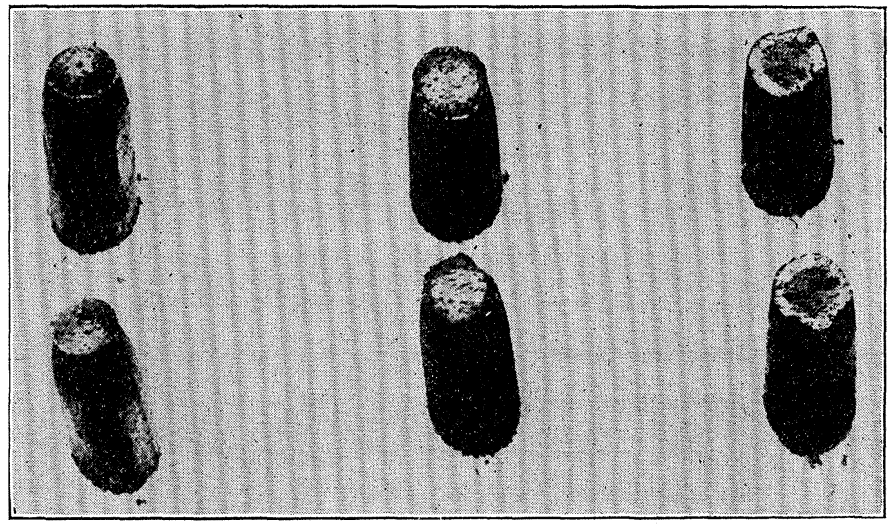

Fig. 4.

Shows the fracture of cold-rolled steel broken under stress. $A$ and $B$ without exposure to hydrogen. $C$ exposed 40 seconds to electrolytic hydrogen. The bright band shows depth of penetration.

with which electrolytic hydrogen penetrates mild steel. $A, B$, and $C$ are test specimens, $6 \mathrm{~mm}$. in diameter, cut from the same rod of coldrolled steel. $A$ and $B$ were broken under stress without exposure to hydrogen. $C$, on the other hand, was broken after an exposure of 40 seconds. The bright band of this test piece indicates the depth of penetration of the hydrogen during this interval.

An investigation which is in progress on a wide range of steels shows that both the magnetic permeability and the specific resistance decrease on exposure of the metal to the electrolytic hydrogen. It is hoped that when this work is reported, a complete explanation of the changes taking place within the metal will be given.

I wish to acknowledge the valuable assistance given me by Mr. W. O. Smith, who has helped me in all the work.

\footnotetext{
University of Pittsburgh,

PitTsburgh, Pa.

${ }^{1}$ Coulson, Am. Electro-Chem. J., I9I 7.
} 


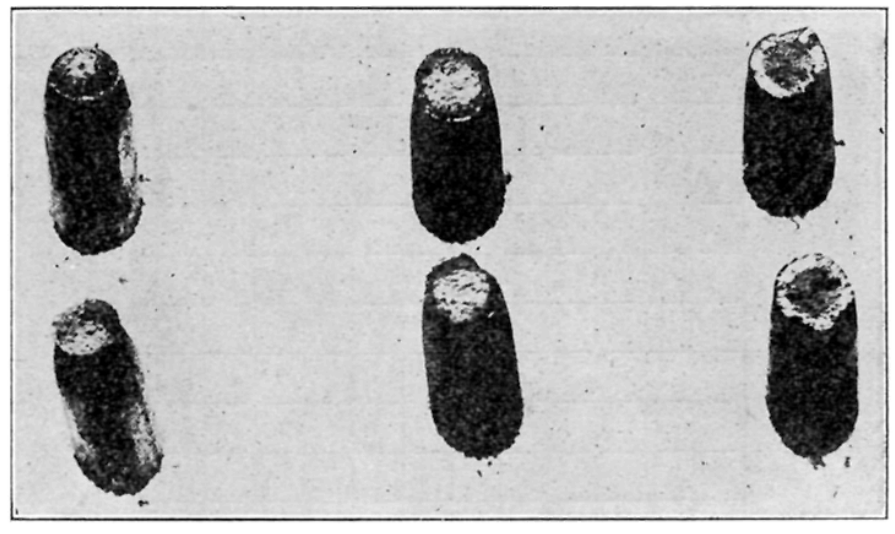

Fig. 4. 